\title{
Clinical Reliability of Different Facial Measurements in Determining Vertical Dimension of Occlusion in Dentulous and Edentulous Subjects
}

\author{
${ }^{1}$ Anchal Brar, ${ }^{2}$ Khurshid A Mattoo, ${ }^{3}$ Yashpal Singh, ${ }^{4}$ Manas Singh, ${ }^{5}$ Puneet Raj Singh Khurana, ${ }^{6}$ Mayank Singh
}

\begin{abstract}
Purpose: To determine the variations in average distances between various facial landmarks used to determine the vertical dimension of rest and occlusion among dentulous and edentulous subjects. Besides determining the reliability of these facial measurements against commonly used Chin-Nose distance, this study would also compare the difference between cephalometric landmarks (anterior nasal Spine-Menton) with the Chin-Nose distance (Niswonger's method).
\end{abstract}

Materials and methods: To standardize the measurement and minimize errors associated with observer and subject movement, a novel instrument was designed in the form of an apparatus and was named as subject and device stabilizing apparatus (SDSA). One hundred and twenty subjects, in the age group of 30 to 60 years, were selected and divided into two equal groups which were further subdivided into subgroups. Measurements were recorded with the help of a digital vernier that was attached to the apparatus. The various facial measurements studied were Pupil-Stomion, Glabella-Subnasion, Pupil-Pupil and Angle-Angle both at rest and in occlusion. These measurements were then compared with Chin-Nose and anterior nasal Spine-Menton distance. Differences between the dentulous and edentulous subjects at rest and at occlusion were noted and statistically analyzed using unpaired 't' test and Karl Pearson correlation coefficient.

Results: Among the six measurements Chin-Nose, GlabellaSubnasion, Pupil-Stomion and anterior nasal Spine-Menton were closely associated between dentulous and edentulous subjects both at rest and at occlusion. Among all facial and

\footnotetext{
${ }^{1,4,6}$ Senior Lecturer, ${ }^{2}$ Assistant Professor, ${ }^{3,5}$ Reader

${ }^{1}$ Department of Prosthodontics, Kalka Dental College, Meerut University, Meerut, Uttar Pradesh, India

${ }^{2}$ Department of Prosthodontics, College of Dental Sciences Gizan, Saudi Arabia

${ }^{3}$ Department of Prosthodontics, Subharti Dental College, Meerut Uttar Pradesh, India

${ }^{4,5}$ Department of Prosthodontics and Crown and Bridge, Institute of Dental Education and Advance Study, Gwalior, Madhya Pradesh, India

${ }^{6}$ Department of Prosthodontics and Crown and Bridge, King George's Medical University, Lucknow, Uttar Pradesh, India

Corresponding Author: Anchal Brar, Senior Lecturer Department of Prosthodontics, Kalka Dental College, DelhiHaridwar Bypass, NA 58, Meerut, Uttar Pradesh, India, e-mail: anchalbrar@ymail.com
}

cephalometric measurement the facial parameter of PupilStomion illustrates the least deviation in edentulous (1.318) and dentulous (1.381) subjects at rest, whereas anterior nasal Spine-Menton displays least deviation in edentulous (2.751) and dentulous (1.224) subjects at occlusion.

Conclusion: The average facial measurements in dentulous subjects were more than measurements in edentulous subjects and among various facial measurements, Pupil-Stomion and anterior nasal Spine-Menton distance can be used clinically as a guide to verify vertical dimension of occlusion.

Keywords: Occlusion, Facial parameters, Jaw relations, Occlusal plane.

How to cite this article: Brar A, Mattoo KA, Singh Y, Singh M, Khurana PRS, Singh M. Clinical Reliability of Different Facial Measurements in Determining Vertical Dimension of Occlusion in Dentulous and Edentulous Subjects. Int J Prosthodont Restor Dent 2014;4(3):68-77.

Source of support: Nil

Conflict of interest: None

\section{INTRODUCTION}

A delicate balance exists between restoration of physiological functions and preservation of supporting structures in completely edentulous patients seeking complete denture prosthesis. Plan to preserve the remaining residual alveolar ridges starts right from first to follow-up visits, but certain steps like establishing vertical dimension of occlusion demand special attention. Negligence and carelessness during estimation of vertical dimensions of occlusion (VDO) can lead to rapid resorption of the residual alveolar ridges. Since decades, this critical step has prompted many prosthodontist's to find a constant anthropometric measurement within the face. ${ }^{1}$ On the other hand, attempts to find constant somewhere within the facial pattern has emphasized the fact that variation, and not constancy, is the rule. ${ }^{2,3}$ Prosthodontist's no doubt, are confronted with an infinite variety of facial patterns. ${ }^{4,5}$ Vertical dimensions of the face show infinite variables in a dentulous patient and are dependent on multiple factors. The problem with edentulous state magnifies because the vertical dimension associated with 'sinking-in' of the lips is greater than the occlusal vertical dimension made before the teeth were extracted. The 
facial change is not the result of a decrease in the vertical dimension, but rather by loss of support given to the lips by the teeth and alveolar processes. ${ }^{6}$ Restoring the lost vertical dimensions should be either same as probably what existed prior to the edentulous state or should be in harmony with the existing state of edentulousness.

The determination of the VDO is an important procedure in the treatment of the edentulous patient. ${ }^{7-10}$ According to Ramjford and Ash, ${ }^{11} 10 \mathrm{~mm}$ of interocclusal space may be as 'normal' for one individual as $1 \mathrm{~mm}$ for another. Attempts to change the relationship between the jaws and muscles of an individual to suit an average are to invite failure. The mandibular musculature is the determining factor in the total face height. ${ }^{12}$ An increase of pressure or tension beyond the limits of tolerance leads to the destruction of bone by resorption. This would account for the premature resorption of residual alveolar bone when the occlusal vertical dimension is increased beyond the physiologic limits of the musculature. The amount of interocclusal distance or freeway space that an edentulous patient should have is totally arbitrary. Moreover, there is as much variation in the amount of freeway space as there is in the size of teeth, size of noses, or size of persons.

Many methods to determine the vertical dimension for the rehabilitation of edentulous patients are described in the literature. Facial dividers and soft tissue measurements are still taught today, despite criticism. ${ }^{13-16}$ Occlusal biting pressure $\mathrm{e}^{17-19}$ and swallowing ${ }^{20}$ are used but have also been criticized. ${ }^{21-23}$ Phonetics are popular as a guide for the vertical dimension of occlusion. ${ }^{24}$ Cephalometric has been shown to be a more objective method, but it is two-dimensional and static. ${ }^{6}$ Electromyography is not clinically practical, although it is a valuable research tool. ${ }^{25-28}$ Supplemental electronic methods, ${ }^{29}$ such as telemetry and hall effect devices, ${ }^{30}$ are similarly impractical for the clinician.

Despite conflicting evidence in the literature regarding the measuring of the vertical dimension in edentulous patients, the use of facial reference points is still a popular method in clinical practice, and both the caliper and the Willis gauge techniques are used in research studies. ${ }^{31-34}$ This is due to the fact that these methods do not require sophisticated instruments. More importantly to those who have studied the rest position and centric position $^{35-38}$ of the mandible, in all of their methods, it was evident that a great deal of skill and clinical sensitivity must be employed by the observer to determine these positions, especially in the edentulous patient.

The present study was therefore undertaken to determine the reliability of various facial measurements in determining the VDO. This was achieved by determining the average distances between various facial landmarks (Chin-Nose, Glabella-Subnasion, Pupil-Stomion, PupilPupil, Angle of the mouth to Angle of the mouth) and compare them in dentulous and edentulous subjects. Variations between facial landmarks would determine the reliability of these parameters with commonly used facial landmarks like Chin-Nose distance (Niswonger's method). The study was also intended to compare the difference in percentile between cephalometric landmarks [(anterior nasal spine (ANS)-Menton)] and the Chin-Nose distance (Niswonger's method).

\section{MATERIALS AND METHODS}

Ethical clearance was obtained from the ethical committee of university, before commencing the study. A written informed consent was obtained from all subjects in relation to the study. One hundred and twenty subjects, in the age group of 30 to 60 years, were selected for the study. The subjects were divided into two equal groups, group E (edentulous) and group D (dentulous). The dentulous subjects were selected on the basis of having minimum twenty eight natural permanent teeth, class I molar relationship, no history of injury to face, no relevant chronic systemic medical or local dental problems, no excessive, abnormal soft tissue over the face, with normal breathing pattern and no history of orthodontic treatment in the past. The edentulous subjects selected for the study were those who had no history of any type of wearing prosthesis, had a class I ridge relation and were edentulous not more than a year, no relevant medical problems. In addition the subjects in both groups had a bilaterally symmetrical face (with no evidence of atrophy, hypertrophy, deviated nasal septum, dysphagia and any underlying bone pathology), no moustache, beard or any accessory wear. All the subjects belonged to the northern part of India and were randomly selected.

\section{Subject and Device Stabilizing Apparatus}

A review of previous prosthodontic and orthodontic research reveals that measurements between two landmarks of the face have been taken directly on the patients face, holding a caliper manually. The accuracy of such readings can be questioned because the measuring device when held in hand or the subject's head on which the measurements are made can easily shift. Due to this the operator who is recording the distance between two points on the face can incorporate errors. Keeping these limitations of such methods things in mind, a new apparatus was designed which would minimize such errors (Fig. 1). The apparatus consisted of a horizontal platform or base with four plastic adjustable pins that could be raised or lowered 


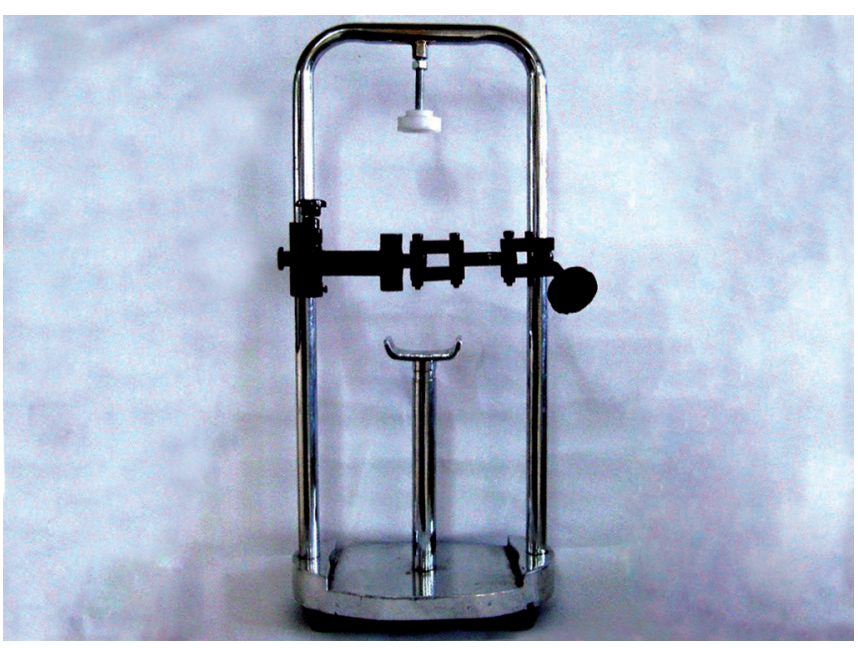

Fig. 1: Subject and device stabilizing apparatus

to position the device parallel to the floor. To this platform, a 'U'-shaped hollow frame was attached which suspends a head positioner from the top. A chin rest with adjustable vertical stand along with a locking device is attached in the center of the platform. A horizontal swiveling arm, is attached to one side of the ' $U$ '-shaped frame and has three components, namely a swiveling arm, which has four detachable, movable and adjustable short horizontal components, an attachment for vernier or any other measuring device connected to the rest through a ball and socket joint and a magnetic disk that locks the vernier in place. In order to accommodate variations in dimensions of human subjects, the dimensions of the apparatus were developed after studying different dimensions of various human races (Fig. 2).

\section{Methodology}

The study subjects were divided into two groups, namely group E (edentulous) and group D (dentulous). For the purpose of statistical analysis the divided groups were further categorized and their readings were recorded under four subgroups namely Edentulous at rest (ER), edentulous in occlusion (EO), dentulous at rest (DR) and dentulous in occlusion (DO). In both the groups, a thorough case history was recorded and clinical examination was conducted. For group A, complete dentures with balanced articulation were fabricated following ideal complete denture prosthodontic protocol. The vertical dimensions that were incorporated for each subject was evaluated using a modified Niswongers method which was verified using physiological methods and approved by five different experienced prosthodontist's to ensure correct vertical dimensions were established. After fabrication of complete dentures the procedure of measuring various facial landmarks was done. The measurements were first measured in their completely edentulous state after which all subjects placed their respective set of

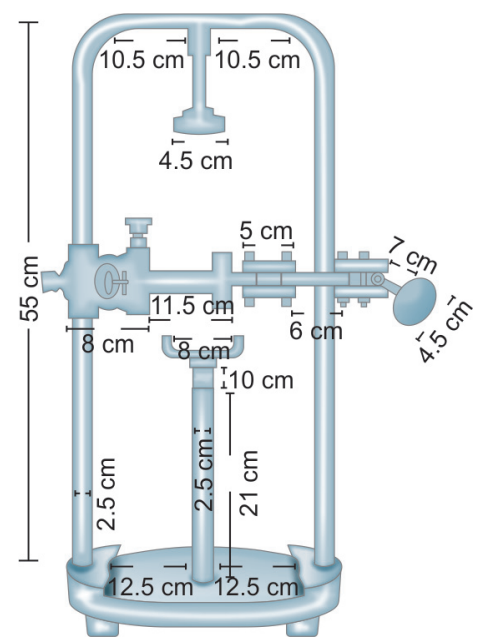

Fig. 2: Dimensions of the SDSA

complete denture prosthesis and measurements were again taken. Cephalometric radiographs were then taken at rest and at occlusion for the subjects belonging to this group. Similarly, facial measurements and cephalometric radiographs were taken from the subjects selected for group D (dentulous) at rest and in occlusion. The measurement of the face at rest and occlusion were recorded using digital vernier calliper which was attached to the magnetic disk of the horizontal arm of the subject and device stabilizing apparatus (SDSA). In addition to the magnetic retention a strip of Velcro band was also attached to the magnetic disk and the base of the vernier. This was done so that it could hold the weight of the vernier. For measurements, subjects were made to sit on a chair with the chin resting on chin rest of the apparatus SDSA. The parietal part of the head was held firmly by the vertical head positioner suspending from the ' $U$ ' shaped frame. The ball and socket attachment of the magnetic disk allowed the vernier to be moved in the vertical direction without moving the entire horizontal arm within the $u$ frame. Three readings for each measurement were taken and the average of the three readings was calculated and recorded.

For cephalometric readings, two lateral radiographs were taken for each subject in both groups, one at rest and one at occlusion. The thin tracing paper was fixed on X-ray film with cello tape and this assembly was placed on X-ray viewer. The tracings were done with sharp lead pencil. The vertical dimension of each patient was then calculated by measuring ANS-Menton distance. This distance was compared with the Chin-Nose distance of each patient.

For facial landmarks, the relevant soft tissue points were palpated and then marked on each individual subject's face with an indelible pencil. All the marks that were marked on subjects were evaluated by expertise in surface anatomy of the human face. The points included Glabella, Subnasion, tip of the nose, center of the pupil 


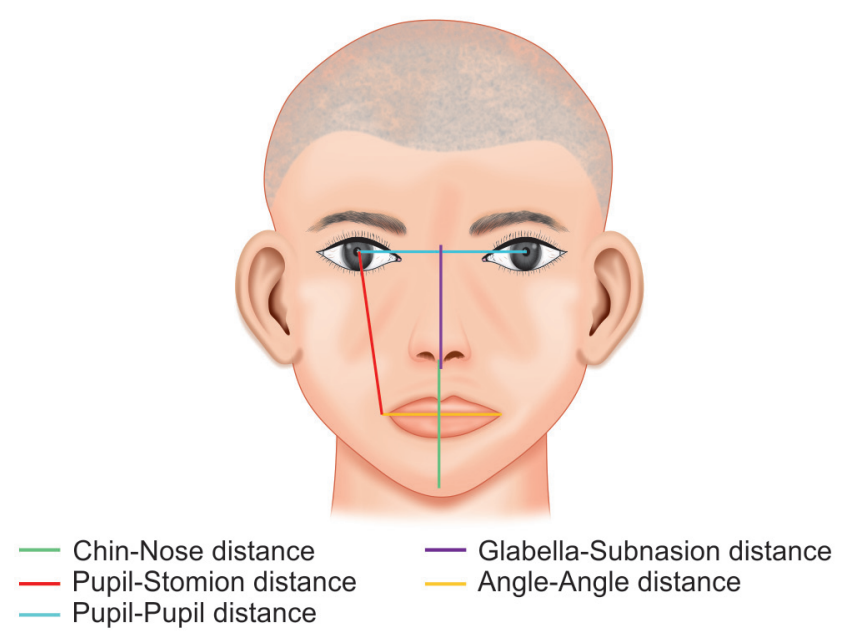

Fig. 3: Facial parameters analyzed in the study

marked on the skin of the upper eyelid, Rima oris and Menton. The facial measurements recorded were between the Glabella and Subnasion, Pupil and Rima Oris, Chin and tip of the nose, center of the Pupil to Stomion and finally between the two angles of the mouth. The following method was carried to measure the various distances.

\section{Pupil-Rima Oris Distance}

The distance between the center of the pupil and a line projected laterally from the resting median line between the upper and lower lips was measured. The subjects were first asked to focus at a point which was about six feet distance in front of them. This allows the individual eyes to be aligned in the center. The patients were then instructed to close the eyelids without changing the position of the eye. To verify that the patient was able to carry such an exercise without error, the patients were asked to open the eyelids again. This would verify the correct position of the eyes. The point of greatest convexity over the closed upper eyelid was considered to be the center of the pupil. This point was marked with a tissue marking pencil. The external jaws of the vernier were then placed at two points and the distance automatically was displayed on the LCD display of the vernier. The measurements were recorded for all groups.

\section{Glabella-Subnasion Distance (Fig. 3)}

The distance between the glabella (point of greatest prominence between the 2 eyebrows) and the base of the nose was recorded while the subjects head would rest in between the chin rest and the head positioned of the SDSA. The base of the nose was lightly touched by the external jaws of the calliper. The measurements were made for all subgroups.

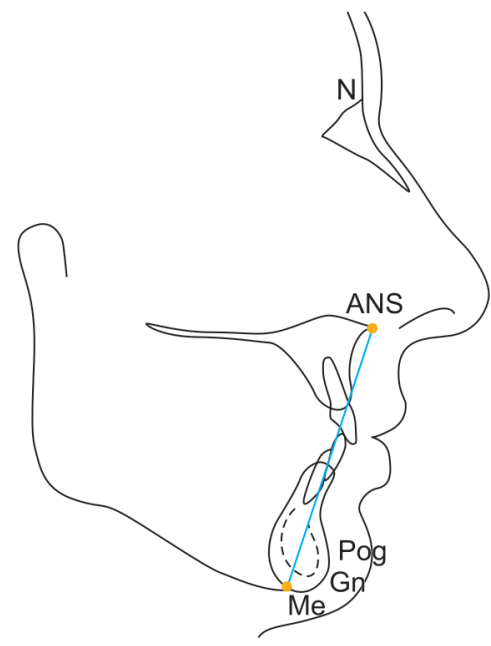

Fig. 4: Cephalometric landmarks compared against Chin-Nose distance

\section{Chin-Nose Distance}

Much emphasis has been laid on these two landmarks as they are easy to be measured clinically with a simple scale. Firstly the most prominent part of the nose tip and the chin were marked with an indelible pencil. The horizontal arm of the SDSA was then adjusted so that the external jaws of the vernier were in line with these two points. The distance between the two points was measured three times for all subgroups within each group.

\section{Distance between the Center of the Pupil to Stomion}

The distance between the center of the Pupil and the Stomion (the line joining the lips in median line and not the corner of the mouth) was likewise measured while the patient's head was in SDSA.

\section{Distance between Right and Left Angle of the Mouth}

This is a horizontal distance that was measured while the subject's mandible was in physiologic rest position and in centric occlusion.

\section{ANS-Menton Distance (Figs 4 and 5)}

The distance between the base of the nose indicated by anterior nasal spine and menton (the lowest most point on the bony chin) was measured on cephalometric radiograph. This measurement was recorded for all subjects in both subgroups of each group.

The results obtained were put to statistical analysis. Mean and standard deviations were obtained first. This was followed by obtaining the comparisons between various groups by applying unpaired ' $t$ ' test where,

$$
S=\sqrt{\frac{\left\{\left(n_{1}-1\right)\left(S_{1}\right)^{2}+\left(n_{2}-1\right)\left(S_{2}\right)^{2}\right\}}{\left(n_{1}-n_{2}-2\right)}} .
$$




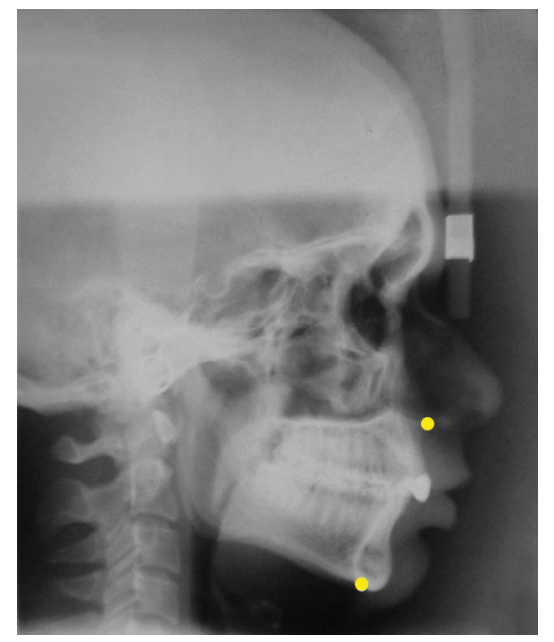

Fig. 5: Lateral cephalogram showing the two related points

Karl Pearson correlation coefficient was used to obtain the correlation between Chin-Nose distance and other various facial measurements.

\section{RESULTS}

The study evaluated the reliability of different facial measurements in determining the vertical dimension of occlusion in the edentulous and dentulous subject. Three recordings of every facial parameter measurement were made for each subject, from which a mean was calculated. This was followed by calculation of mean between all subjects of that group. Statistical analysis with unpaired ' $t$ ' test, found significant values for Chin-Nose (0.04), Glabella-Subnasion (0.02), Pupil-Stomion (0.03) and ANS-Menton (0.04) between edentulous at rest (ER) and

Table 1: Probable value of unpaired 't'-test between edentulous and dentulous group at rest for different facial parameters

\begin{tabular}{llll}
\hline $\begin{array}{l}\text { S. } \\
\text { no. }\end{array}$ & Facial parameters & $\begin{array}{l}\text { Probable value of } \\
\text { 't'(unpaired) }\end{array}$ & $p$-value \\
\hline 1. & Chin-Nose & 0.043 & $<0.05 \mathrm{~S}^{*}$ \\
2. & Glabella-Subnasion & 0.029 & $<0.05 \mathrm{~S}^{*}$ \\
3. & Pupil-Stomion & 0.037 & $<0.05 \mathrm{~S}^{*}$ \\
4. & Pupil-Pupil & 0.108 & $>0.05 \mathrm{NS}$ \\
5. & Angle-Angle & 0.17 & $>0.05 \mathrm{NS}$ \\
6. & Anterior nasal spine & 0.044 & $<0.05 \mathrm{~S}^{*}$ \\
& (ANS)-Menton & & \\
\hline
\end{tabular}

${ }^{*} p<0.05$ shows a significant difference at $5 \%$ level of significance; S: Significant; NS: Nonsignificant dentulous at rest (DR) groups at rest position (Table 1). The facial parameters of Chin-Nose (0.03), Glabella-Subnasion (0.04), Pupil-Stomion (0.02) and ANS-Menton (0.04) between edentulous at occlusion (EO) and dentulous at occlusion (DO) groups at occlusion were also having significant values at $\mathrm{p}<0.05$ (Table 2). In edentulous group edentulous at rest (ER), the facial landmark of the Pupil-Stomion (0.99 to 1) and ANS-Menton (0.98 to 1) shows a close resemblance to Chin-Nose distance at rest (Table 3). Within the same edentulous group edentulous at occlusion (EO) these two facial parameters again show close proximity to the Chin-Nose distance in occlusion (0.96 and 0.98 to 1 respectively) (Table 4). The ANS-Menton facial parameter showed more close values to Chin-Nose distance in the other group dentulous at rest (DR) both at rest (0.99 to 1) and dentulous at occlusion (DO) (0.98 to 1) (Tables 5 and 6). In the edentulous state of rest the facial parameter of Pupil-Stomion shows the least deviation with Chin-Nose distance (1.318) whereas in occlusion the ANS-Menton parameter shows the least percentage of deviation (2.751). In the dentulous group, Pupil-Stomion shows the least deviation (1.381) at rest and ANS-Menton shows the least deviation in occlusion (1.224) (Tables 7 and 8). Relation of ANS Menton to Chin-Nose distance is depicted in Graph 1 (edentulous) and Graph 2 (dentulous).

\section{DISCUSSION}

Determining occlusal vertical dimensions is significant in oral rehabilitation be it complete denture prosthesis, full mouth rehabilitation, crown and bridge prosthesis, orthodontic correction of malaligned or malpositioned

Table 2: Probable value of unpaired t-test between edentulous and dentulous group at occlusion for different facial parameters

\begin{tabular}{llcl}
\hline $\begin{array}{l}\text { S. } \\
\text { no. }\end{array}$ & Facial parameters & $\begin{array}{l}\text { Probable value of } \\
\text { t' (unpaired) }\end{array}$ & $p$-value \\
\hline 1. & Chin-Nose & 0.037 & $<0.05 \mathrm{~S}^{*}$ \\
2. & Glabella-Subnasion & 0.043 & $<0.05 \mathrm{~S}^{*}$ \\
3. & Pupil-Stomion & 0.025 & $<0.05 \mathrm{~S}^{*}$ \\
4. & Pupil-Pupil & 0.21 & $>0.05 \mathrm{NS}$ \\
5. & Angle-Angle & 0.16 & $>0.05 \mathrm{NS}$ \\
6. & ANS-Menton & 0.047 & $<0.05 \mathrm{~S}^{*}$ \\
\hline
\end{tabular}

${ }^{*} p<0.05$ shows a significant difference at $5 \%$ level of significance; S: Significant; NS: Nonsignificant

Table 3: Karl Pearson correlation coefficient among different facial parameters for edentulous group at rest

\begin{tabular}{lllllll}
\hline & Chin-Nose & $\begin{array}{l}\text { Glabella- } \\
\text { Subnasion }\end{array}$ & Pupil-Stomion & Pupil-Pupil & Angle-Angle & ANS-Menton \\
\hline Chin-Nose & 1 & & & & & \\
Glabella-Subnasion & 0.89 & 1 & 1 & & & \\
Pupil-Stomion & 0.99 & 0.90 & 0.94 & 1 & & 1 \\
Pupil-Pupil & 0.97 & 0.79 & 0.85 & 0.77 & 0.83 & 1 \\
Angle-Angle & 0.84 & 0.85 & 0.97 & 0.97 & 0.97 \\
ANS-Menton & 0.98 & 0.83 & & & & \\
\hline
\end{tabular}




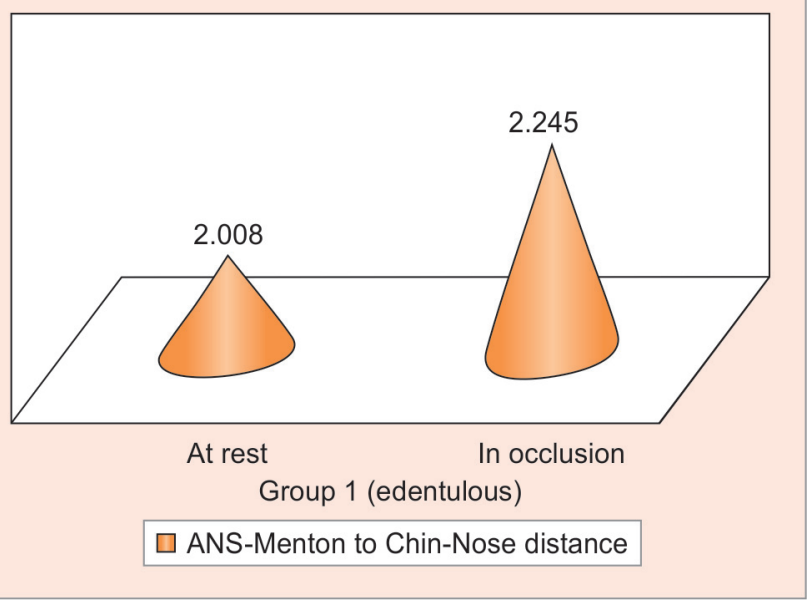

Graph 1: Relation of ANS-Menton to Chin-Nose distance in edentulous subjects

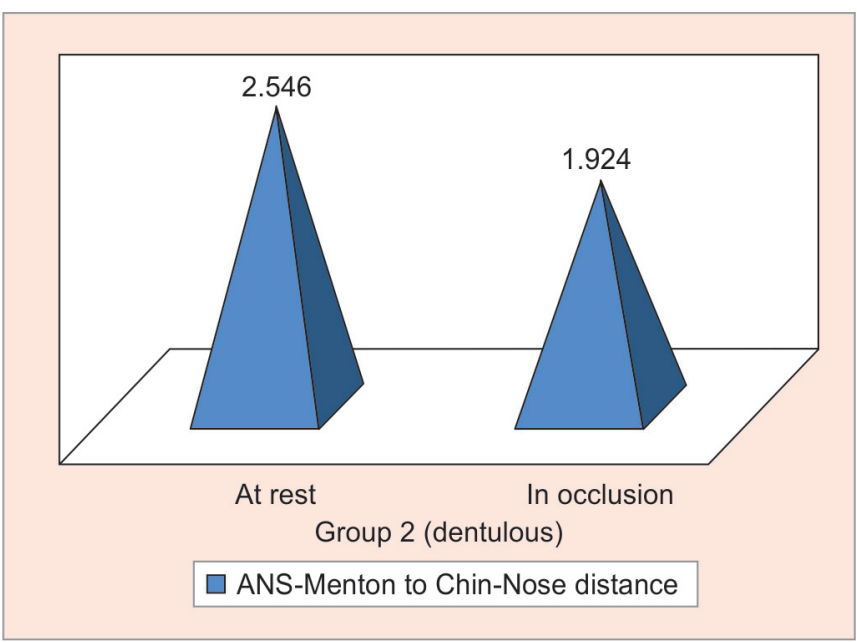

Graph 2: Relation of ANS-Menton to Chin-Nose distance in dentulous subjects

Table 4: Karl Pearson correlation coefficient among different facial parameters for edentulous group at occlusion

\begin{tabular}{|c|c|c|c|c|c|c|}
\hline & Chin-Nose & $\begin{array}{l}\text { Glabella- } \\
\text { Subnasion }\end{array}$ & Pupil-Stomion & Pupil-Pupil & Angle-Angle & ANS-Menton \\
\hline Chin-Nose & 1 & & & & & \\
\hline Glabella-Subnasion & 0.93 & 1 & & & & \\
\hline Pupil-Stomion & 0.96 & 0.86 & 1 & & & \\
\hline Pupil-Pupil & 0.91 & 0.77 & 0.89 & 1 & & \\
\hline Angle-Angle & 0.91 & 0.87 & 0.88 & 0.78 & 1 & \\
\hline ANS-Menton & 0.97 & 0.90 & 0.91 & 0.92 & 0.85 & 1 \\
\hline
\end{tabular}

Table 5: Karl Pearson correlation coefficient among different facial parameters for dentulous group at rest

\begin{tabular}{lllllll}
\hline & Chin-Nose & $\begin{array}{l}\text { Glabella- } \\
\text { Subnasion }\end{array}$ & Pupil-Stomion & Pupil-Pupil & Angle-Angle ANS-Menton \\
\hline Chin-Nose & 1 & & & & & \\
Glabella-Subnasion & 0.96 & 1 & 1 & & & \\
Pupil-Stomion & 0.99 & 0.93 & 0.94 & 1 & & 1 \\
Pupil-Pupil & 0.97 & 0.96 & 0.93 & 0.95 & 0.95 & 1 \\
Angle-Angle & 0.94 & 0.91 & 0.99 & 0.96 & \\
ANS-Menton & 0.99 & 0.95 & & & & \\
\hline
\end{tabular}

Table 6: Karl Pearson correlation coefficient among different facial parameters for dentulous group at occlusion

\begin{tabular}{|c|c|c|c|c|c|c|}
\hline & Chin-Nose & $\begin{array}{l}\text { Glabella- } \\
\text { Subnasion }\end{array}$ & Pupil-Stomion & Pupil-Pupil & Angle-Angle & ANS-Menton \\
\hline Chin-Nose & 1 & & & & & \\
\hline Glabella-Subnasion & 0.95 & 1 & & & & \\
\hline Pupil-Stomion & 0.96 & 0.90 & 1 & & & \\
\hline Pupil-Pupil & 0.90 & 0.92 & 0.86 & 1 & & \\
\hline Angle-Angle & 0.93 & 0.91 & 0.93 & 0.91 & 1 & \\
\hline ANS-Menton & 0.98 & 0.93 & 0.98 & 0.89 & 0.94 & 1 \\
\hline
\end{tabular}

Table 7: Percentage of deviation with Chin-Nose distance for edentulous group at rest and occlusion

\begin{tabular}{llll}
\hline $\begin{array}{l}\text { S } \\
\text { no. }\end{array}$ & $\begin{array}{l}\text { Facial } \\
\text { parameter }\end{array}$ & $\begin{array}{l}\text { Edentulous (rest) } \\
\text { (in percentage) }\end{array}$ & $\begin{array}{l}\text { Edentulous (occlusion) } \\
\text { (in percentage) }\end{array}$ \\
\hline 1. & $\begin{array}{l}\text { Glabella- } \\
\text { Subnasion }\end{array}$ & 3.171 & 3.261 \\
2. & Pupil-Stomion & 1.318 & 2.976 \\
3. & Pupil-Pupil & 6.105 & 3.693 \\
4. & Angle-Angle & 4.034 & 5.475 \\
5. & ANS-Menton & 2.008 & 2.751 \\
\hline
\end{tabular}

Table 8: Percentage of deviation with Chin-Nose distance for dentulous group at rest and occlusion

\begin{tabular}{llll}
\hline S & $\begin{array}{l}\text { Facial } \\
\text { no. }\end{array}$ & $\begin{array}{l}\text { Dentulous (rest) } \\
\text { (in percentage) }\end{array}$ & $\begin{array}{l}\text { Dentulous (occlusion) } \\
\text { (in percentage) }\end{array}$ \\
\hline 1. & $\begin{array}{l}\text { Glabella- } \\
\text { Subnasion }\end{array}$ & 2.241 & 3.091 \\
2. & Pupil-Stomion & 1.381 & 2.171 \\
3. & Pupil-Pupil & 4.106 & 3.749 \\
4. & Angle-Angle & 5.039 & 4.94 \\
5. & ANS-Menton & 2.126 & 1.224 \\
\hline
\end{tabular}


teeth whose correction can lead to change in vertical dimension of occlusion. Physiological rest position of the mandible and the freeway space form the basis of vertical dimension estimation and has been discussed by many authors in the literature. ${ }^{39-50}$ Significance of vertical dimensions and its alterations has also been stressed by many disciplines. ${ }^{51-62}$ Various methods have been described in the literatures which are both subjective as well as objective. The subjective methods comprise of evaluation of esthetics, ${ }^{41,63-69}$ phonetics, ${ }^{14,24,70-73}$ swallowing ${ }^{20,22,74-76}$ and patient comfort. ${ }^{19,77}$ The objective methods comprise of electromyographic records, ${ }^{78}$ biting power, ${ }^{17,79,80}$ utilization of facial measurements. ${ }^{13,36,81-93}$ Different radiographic methods have also been advocated in determining the VDO. ${ }^{8,94-96}$

The traditional methods, including the judgment of facial esthetics and patient comfort sounds well subjectively but are too nonspecific scientifically. Aids, such as tooth display, lip support, harmonious relationship and facial picture do not substantiate for those patients in whom no factual records exist. The objective method like electromyography and biting forces are impractical as they necessitate the use of complex devices and cannot be routinely used. As there is still no positive method recapturing the original position and pitch of the upper anterior teeth in case of an edentulous patient. Hence, the use of facial dimensions for establishing the occlusal vertical dimension can be considered to be more practical objectively and subjectively. The present study was therefore directed to determine the relationship of vertical dimension of rest and occlusion with other facial measurements. These included the distance between the center of pupil to stomion, Chin-Nose distance, glabellasubnasion distance, the distance between two angles of the mouth, the distance between two pupils. The ChinNose distance was verified with bony landmarks on a cephalogram, i.e. anterior nasal spine to menton distance. The most commonly practiced facial measurements in complete denture prosthodontics is the Chin-Nose distance. The mandible is an ever changing and a mobile member of the cranium, any landmark or measurement which does not involve the mandible will minimize errors in recording. $\mathrm{McGee}^{80}$ and Pound ${ }^{68}$ in their study considered vertical dimension to be the distance between subnasion and gnathion. However, in the present study, the vertical dimension was measured as the distance between the tip of the nose and chin as suggested by Niswonger. ${ }^{14}$

The results of the study showed that the Chin-Nose distance in the selected subjects lay in the range of 50 to $75 \mathrm{~mm}$ with the mean of $64 \mathrm{~mm}$ in edentulous subject at rest position and $61 \mathrm{~mm}$ in occlusion. This would establish a mean freeway space of $3 \mathrm{~mm}$. Keeping this as a standard, other facial measurements can be analyzed. Niswonger ${ }^{14}$ did a similar study in which he found out that when an interocclusal clearance of $4 / 32$ inch was used for 50 edentulous patients, dentures were satisfactory. The presence or absence of denture was also found to have a profound influence on the Chin-Nose distance which was in accordance with the statement of Atwood ${ }^{50}$ who confirmed a momentous difference in vertical dimension with and without denture. The Chin-Nose distance for dentulous group lies in the range of 54 to $80 \mathrm{~mm}$ with the mean of $69 \mathrm{~mm}$ for dentulous subject at rest position and $66 \mathrm{~mm}$ in occlusion, thereby establishing a freeway space of $3 \mathrm{~mm}$. The presence or absence of denture was also found to have profound influence on the Chin-Nose distance which was in accordance with the statement of Atwood ${ }^{50}$ who confirmed a momentous difference in vertical dimension with and without denture. The Chin-Nose distance for dentulous group lies in the range of 54 to $80 \mathrm{~mm}$ with the mean of $69 \mathrm{~mm}$ for dentulous subject at rest position and $66 \mathrm{~mm}$ in occlusion, thereby establishing a freeway space of $3 \mathrm{~mm}$.

Pupil-Stomion distance shows among all other facial measurements a strong correlation with Chin-Nose distance. This distance in group ER showed $99 \%$, in group EO 98\%, in group DR it shows $99 \%$ close relation and in group DO it came next to ANS-Menton distance, i.e. $96 \%$. The ANS-Menton distance evaluated on cephalographs shows the close relation of up to $98 \%$ in group ER, $95 \%$ in EO, $98 \%$ in DR and $98 \%$ in group DO. The Angle-Angle, distance shows least correlation with Chin-Nose distance when compared with all other facial measurements. This distance in group ER showed $83 \%$ similarity, in group DR $94 \%$ similarity and, in group EO, DO, it came next to Pupil-Pupil distance, i.e. 91 and $92 \%$ similarity to Chin-Nose distance respectively. These results conclude that Pupil-Pupil and Angle-Angle are not a reliable determinant for the vertical dimension of occlusion. $\mathrm{McGe}^{80}$ advocated the use of facial dimension, namely Pupil-Rima oris distance, Glabella-Subnasion distance, the distance from one corner of the mouth to another and subnasion-gnathion distance. He claimed that $95 \%$ of the subjects with natural teeth, two of these measurements corresponded to the occlusal vertical dimension.

Similarity between the facial measurements in both the groups (edentulous and dentulous) were seen with highly statistically significant difference in Chin-Nose, Pupil-Stomion, Glabella-Subnasion and ANS-Menton distance with their values being more in dentulous subject, and agrees with the conclusions of Tallgreen ${ }^{47}$ and Coccaro and Lloyd ${ }^{58}$ who noted a reduction in the facial height with the first year of edentulousne. The 
reduction in facial height following extraction of all the teeth within the first year of edentulousness is due to the fact that there is maximum resorption of residual ridges during this period leading to utmost loss of vertical dimension. The present study also included subjects within the first period of edentulousness.

Due to the subjective criterion for the determination of occlusal vertical dimension, i.e. patient comfort and tactile sensation there is always a likelihood of fabrication of dentures at a vertical dimension less than the pre-extraction vertical dimension, which is due to the belief that the patient had the propensity to favor decreased vertical dimension as pointed out by Garnick and Ramjford ${ }^{27}$ about the existence of resting range than precise point. Therefore, to overcome this in our study the occlusal vertical dimension was established by measuring the Chin-Nose distance without highlighting the subjective criteria. The difference between the ChinNose distance and other observed facial measurements were calculated. This was done to find out an alternative facial measurement for determination of occlusal vertical dimension in case of absence of pre-extraction records. As anticipated Chin-Nose distance demonstrated a strong positive association with other facial dimension. This could simply be stated that if the face is large there is probability that vertical dimension would also be large. The Chin-Nose distance demonstrated a strong positive association with Pupil-Stomion and ANS-Menton distance. Therefore, in cases where Chin-Nose distance cannot be reliable as a result of clinical conditions affecting the mandible and its associated structure, the Pupil-Stomion measurements of the patients can be taken and incorporated as the VDO in the complete denture prosthesis. The vertical dimension of occlusion can be later verified by the physiological methods. The vertical dimensions verified clinically during jaw relation can also be verified by ANS-Menton distance on cephalographs as bony landmarks on cephalographs give more accurate and reliable readings. The degree of accuracy in measurement is improved by eliminating errors introduced by measuring the same on soft tissue. There are drawbacks of cephalograph other than distortion of image, cost and frequent exposure to X-ray. Another drawback is that cephalometric method may be used as a method of verifying already established vertical dimension by other methods.

Chawla et $\mathrm{al}^{86}$ conducted a study on the North Indian population with edentulous subject in the age group ranging between 40 and 60 years suggesting that the facial measurements, i.e. left angle of eye to angle of mouth distance and left ear-eye distance could be used with reasonable accuracy to determine VDO for a particular denture. The present study does not include such measurement. On evaluating results of the present study, it is observed that the Pupil-Stomion distance and ANS-Menton distance can be used with reasonable precision to compute the occlusal vertical dimension in both dentate and edentulous subjects.

\section{CONCLUSION}

A new innovative apparatus named as SDSA was designed that allows the observer to measure distance between any two points on the face without changing observer's position or the subject's position. Within the limitations of this in vivo study, following can be concluded:

- Among various facial measurements, Pupil-Stomion and ANS-Menton distance can be used clinically as a guide to verify VDO after determining it with any mechanical method.

- The average facial measurements in dentulous subjects were more than measurements in edentulous subjects, indicating that the loss of teeth produces a concomitant decrease in vertical dimension of the face.

- The present study was confined to the North Indian population, and may not be applicable to another population for which further studies are recommended.

- The Pupil-Pupil and Angle-Angle, distance did not have a significant role in determining VDO.

\section{ACKNOWLEDGMENTS}

The authors would like to acknowledge all the subjects, students and other staff and non-staff members of the institute who participated directly or indirectly during the course of the study. The authors would also like to thank the President, Dean and Principal and all Head of Departments for their continuous support toward research.

\section{REFERENCES}

1. Wylie WL. The Naso-Meatal line as a guide for the determination of the occlusal plane. Dent Res 1944;23:309-312.

2. Willis FM. Esthetics of full denture construction. JADA 1930;17:636-641.

3. Moore AW. Observations on facial growth and its clinical significance. Am J Orthodontics 1959;45:399-423.

4. Goldstein A. Potentials in pattern of mandible. Angle Orthodontics 1959;29:206-217.

5. Wylie WL. The relationship between ramus height, dental height and overbite. Am J Orthodontics 1946;32:56-67.

6. Thompson JR. The rest position of the mandible and its significance to dental science. JADA 1946 Feb;33:151-180.

7. Rugh JD, Drago CJ. Vertical dimension: a study of clinical rest position and jaw muscle activity. J Prosthet Dent 1981;45:670-675. 
8. Toolson LB, Smith DE. Clinical measurement and evaluation of vertical dimension. J Prosthet Dent 1982;47:236-241.

9. Fayz F, Eslami A. Determination of occlusal vertical dimension: a literature review. J Prosthet Dent 1988;59: 321-323.

10. McCord JF, Grant AA. Registration: Stage II - Intermaxillary relations. Br Dent J 2000;188:601-606.

11. Ramjford SP, Ash MM. Diagnosis and treatment plan. In: Ramjford SP, Ash M, editors. Occlusion. WB Saunders company, Philadelphia; 1966. p. 102.

12. Wylie WL. Overbite and vertical dimension in terms of muscle balance. Angle Orthodontics 1944;14:13-17.

13. Willis FM. Features of the face involved in full denture prosthesis. Dent Cosmos 1935;77:851.

14. Niswonger ME. The rest position of the mandible and the centric relation. J Am Dent Assoc 1934;20:1572-1576.

15. McMillan DR, Barbenel JC, Quinn. Measurements of occlusal face height by dividers. Dent Pract Dent Ret 1970;20:177.

16. Tryde G, McMillan DR, Christensen J, et al. The fallacy of facial measurements of occlusal height in edentulous patients. J Oral Rehabil 1976;33:353.

17. Boos RH. Intermaxillary relation established by biting power. J Am Dent Assoc 1940;27:1192-1197.

18. Tueller M. The relationship between the vertical dimension of occlusion and forces generated by closing muscles of mastication. J Prosthet Dent 1969;22:284-289.

19. Lytle R. Vertical relationship of occlusion by the patient's neuromuscular preceptor. J Prosthet Dent 1964;14:12-18.

20. Shanahan EJ. Physiologic vertical dimension and centric relation. J Prosthet Dent 1956;6:741.

21. Boucher LJ. Can biting force be used as a criteria for registering vertical dimension. J Prosthet Dent 1959;9:594-599.

22. Ismail J, George A. The consistency of the swallowing technique on determining occlusal vertical dimension in edentulous patients. J Prosthet Dent 1968;19:230-234.

23. Finnegan FJ. Determination of maxillofacial force during deglutition. J Prosthet Dent 1967;17:134-137.

24. Silverman M. Speaking method in measuring vertical dimension. J Prosthet Dent 1953;3:193-195.

25. Moyers R. An electromyographic analysis of certain muscles involved in temporomandibular joint movement. Am J Orthod 1950;36:481-486.

26. Jarabak JR. An EMG analysis of muscular behavior in mandibular movements from rest position. J Prosthet Dent 1957;7:682-685.

27. Garnick J, Ramjford. Rest position of mandible. J Prosthet Dent 1962;12:895-899.

28. Silliamson EH, Woelfel JP, Williams BH. A longitudinal study of rest position and centric occlusion. Angle Orthod 1975;45:130-135.

29. Griffiths MJ. Telemetry and the study of vertical jaw relations. J Prosthet Dent 1975;3:261-265.

30. Lemmer J, Lewin Van Ransburg. The measurement of jaw movement. J Prosthet Dent 1976 Aug;36(2):211-215.

31. Monteith $\mathrm{B}$. The role of the free-way space in the generation of muscle pain among denture-wearers. J Oral Rehabil 1984;11:483-498.

32. Hellsing G, Ekstrand K. Ability of edentulous human beings to adapt to changes in vertical dimension. J Oral Rehabil 1987;14(4):379-383.

33. Mohindra NK, Bulman JS. The effect of increasing vertical dimension of occlusion on facial aesthetics. Br Dent J 2002 Feb 9;192(3):164-168.
34. Gillis, Robert R. Establishing vertical dimension in full denture construction. JADA 1941;28:430-436.

35. Tench RW. Danger in dental reconstruction involving increase of vertical dimension of lower third of human face. JADA 1938;25:566-569.

36. Pleasure MA. Correct vertical dimension and freeway space. JADA 1943;43:160-163.

37. Boos RH. Occlusion from rest position. J Prosthet Dent 1952;2:575-588.

38. Thomas EJ Shanahan. Dental physiology for dentures. J Prosthet Dent 1952;2:3-11.

39. Wallisch, Gottlieb B. Traumatic occlusion and the rest position of the mandible. J Periodont 1906;18:7-20.

40. Sicher H, Tandler J. Mandibular positions. JADA 1928;43:34-38.

41. Thompson JR. A cephalometric study of the movements of the mandible. JADA 1946;28:750-761.

42. Coulombe T. A serial cephalometric study of the rest position of the mandible on edentulous individuals. J Canad DA 1954;20:536-543.

43. Thompson JR, Brodie AG. Factors in the position of the mandible. JADA 1942;29:925-941.

44. Tallgreen. The rest position of the mandible and its significance to dental science. JADA 1957;33:151-57.

45. Thompson JR. Concepts regarding function of the stomatognathic system. J Am Dent Assoc 1954;48:626-637.

46. Atwood DA. A Cephalometric study of the clinical rest position of the mandible. Part I. J Prosthet Dent 1956;6:504-519.

47. Tallgreen A. Changes in adult face height due to aging, wear and loss of teeth and prosthetic treatment. Acta Odont Scandinavia 1957;24:90-97.

48. Shpuntoff H, Shpuntoff W. A study of physiologic rest position and centric position by electromyography. J Prosthet Dent 1956;6:621-625.

49. Ballard CF. A consideration of the physiological background of mandibular posture and movement. D Pratt 1958;6:80-89.

50. Atwood DA. A critique of research of the rest position. J Prosthet Dent 1966;16:84.

51. Landa JS. The importance of phonetics in full denture prosthesis. D Digest 1935;41:154-160.

52. Harris HL. Effect of loss of vertical dimension on anatomic structures of head and neck. JADA 1936;27:175-193.

53. Hight FM. Taking of registration for securing centric jaw relations. JADA 1936;23:1447-1452.

54. Mershon JV. Bite-opening dangers. JADA 1979;26:72-77.

55. Leof M. Study of accepted relation on mandibular position. J Dent 1950;20:8-14.

56. Lammie GA, Perry HT, Crumm BD. Certain observations on a complete denture patient: electromyographic observations. J Prosthet Dent 1954;8:929-939.

57. Yoshizumi DT. An evaluation of the factors pertinent to the success of a complete denture service. J Prosthet Dent 1964;14:866-878.

58. Coccaro PJ, Lloyd RS. Cephalometric analysis of morphologic face height. J Prosthet Dent 1965;15:35-37.

59. Ismail, Sassoouni. A cephalometric study of rest position in edentulous person influence of variations in head position. J Prosthet Dent 1968;5:20-25.

60. Pound E. Utilizing speech to simplify a personalized denture service. J Prosthet Dent 1970;24:586-600.

61. Boucher LJ, Zwemer TJ, Pflughoeft F. Can biting force be used as a criterion for vertical dimension? J Prosthet Dent 1975; 9:594-599. 
62. Massad JJ, Mark E, et al. Determination of vertical dimension: a comparative study. J Oral Rehabil 2004;9:45-49.

63. Brodie AJ. Some recent observations on the growth of the jaws and eruption of the teeth. Angle Orthodontist 1940;10: 63-77.

64. Willie RG. Trends in clinical methods of establishing an ideal interarch relationship. J Prosthet Dent 1958;8:243-251.

65. Turrel AJW. Vertical dimension as it relates to etiology of angular chelosis. J Prosthet Dent 1968;19:119-125.

66. Vig PS, Hewitt AB. Asymmetry of facial skeleton. Angle Orthod 1975;45:125-128.

67. Silverman MM, Meyer M. Pre-extraction records to avoid premature aging of the denture patient. J Prosthet Dent 1950; 5:465-476.

68. Pound E. The mandibular movements of speech and their seven related values. J Prosthet Dent 1966;16:835-843.

69. Silverman MM. Determination of vertical dimension. J Prosthet Dent 2001;45:32-37.

70. Pruzansky S. The application of electromyography to dental research. JADA 1952;44:49-68.

71. Ward BL, Osterholtz RH. Establishing vertical relation of occlusion. J Prosthet Dent 1963;13:432-436.

72. Ismail YH. George WA, Sassouni. Cephalometric study of changes occurring in face height following prosthetic treatment. J Prosthet Dent 1968;19:321-330.

73. Douglas JR, Maritato FR. 'Open Rest' A new concept in the selection of the vertical dimension of occlusion. J Prosthet Dent 1965;15:851.

74. Shpuntoft H, Shpuntoff W. A study of physiologic rest position and centric position by electromyography. J Prosthet Dent 1956;6(5):621-628.

75. Jensen JL. An electromyographic study of face height in complete artificial denture subjects. Northwestern Univ 1959;60:12-18.

76. Moller E. The chewing apparatus. JADA 1966;20:35-37.

77. Smith E. Method of securing centric relation and other positional records in complete denture prosthesis. JADA 1941;28:37-43.

78. Ann LK. Determination of vertical dimension by biting force. Malaysian Dent J 1967;7:23-38.

79. Goodfriend DJ. Symptomatology and treatment of abnormalities of the mandibular articulation. Dent Cosmos 1933;75: 844-847.
80. McGee GF. Use of facial measurements in determining the vertical dimension. J Am Dent Assoc 1951;43:160-163.

81. Harvey W. Investigation and survey of malocclusion and ear symptoms with particular reference to Otic Baro trauma. Br Dent J 1948;85:221-225.

82. Turrell AJW. The pre-extraction recording of the vertical dimension by an intraoral method. Dent Pract Dent Res 1955;6:68-72.

83. Bowmann AJ, Chick AO. A note on facial proportions. $\mathrm{Br}$ Dent J 1962;112:288-289.

84. Smith DE. The reliability of pre-extraction records for complete dentures. J Prosthet Dent 1971;25:592-608.

85. Aboul-Ela LM, Mahmoud KAR. Vertical dimension in complete denture prosthesis. JADA 1977;4:76-79.

86. Chawla C, Prakash H, Duggal R. Facial measurements as a means of determination of vertical dimension. J Ind Prosthet Dent 2000;11:33-41.

87. Geerts GAVM, Stuhlinger ME. A comparison of the accuracy of two methods used by pre-doctoral students to measure vertical dimension. J Prosthet Dent 2004;23:59-66.

88. Brodie AG. Growth pattern of human head from third month to eighth year of life. Am J 1941;68:209-262.

89. Pyott JE, Schaeffer A. Simultaneous recording of centric occlusion and vertical dimension. JADA 1952;44:430-436.

90. Coccaro PJ. Factors in the position of the mandible. JADA 1965;12:70-79.

91. Perry HT. The rest position of the mandible and its significance to dental science. JADA 1974;89:45-50.

92. Chaconas, Gonidis. Evaluation of mandibular rest position in subjects with diverse dentofacial morphology. J Prosthet Dent 1986;8:58-62.

93. Unger JW. Comparison of vertical morphologic measurements on dentulous and edentulous patients. J Prosthet Dent 1990; 64:232-234.

94. Brzoza D. Comparison of the most comfortable mandibular position with the intercuspal position using cephalometric analysis. J Oral Rehabil 2005;9:12-18.

95. Bhat VS, Gopinathan M. Reliability of determining vertical dimension of occlusion in complete dentures: a clinical study. J Ind Prosthet Dent 2006;6:38-42.

96. Basler LF, Douglas JR, Moulton RS. Cephalometric analysis of the vertical dimension of occlusion. J Prosthet Dent 1961;11: 831-835. 